NBER WORKING PAPER SERIES

\title{
HOW WELL CAN THE NEW OPEN ECONOMY MACROECONOMICS EXPLAIN THE EXCHANGE RATE AND CURRENT ACCOUNT?
}

\author{
Paul R. Bergin \\ Working Paper 10356 \\ http://www.nber.org/papers/w10356 \\ NATIONAL BUREAU OF ECONOMIC RESEARCH \\ 1050 Massachusetts Avenue \\ Cambridge, MA 02138 \\ March 2004
}

I thank partic ipants in the 2003 AEA meetings and the CEPR International Capital Markets conference in Rome 2003 for helpful comments. This material is based upon work supported by the National Science Foundation under Grant No. 0109006. Any opinions, findings, and conclusions or recommendations expressed in this material are those of the author and do not necessarily reflect the views of the National Science Foundation. The views expressed herein are those of the authors and not necessarily those of the National Bureau of Economic Research.

(C2004 by Paul R. Bergin. All rights reserved. Short sections of text, not to exceed two paragraphs, may be quoted without explicit permission provided that full credit, including $(\mathbb{C}$ notice, is given to the source. 
How Well Can the New Open Economy Macroeconomics Explain the Exchange Rate and Current Account?

Paul R. Bergin

NBER Working Paper No. 10356

March 2004, Revised March 2006

JEL No. F41

\begin{abstract}
This paper advances the new open economy macroeconomic (NOEM) literature in an empirical direction, estimating and testing a two-country model. Fit to U.S and G-7 data, the model performs moderately well for the exchange rate and current account. Results offer guidance for future theoretical work. Parameter estimates lend support to some common assumptions in the theoretical literature, such as local currency pricing and risk sharing. Estimates are found for key parameters commonly calibrated in the theoretical literature, such as the elasticity of substitution between home and foreign composite goods, and the response of a country risk premium to the net foreign asset position. Results also indicate that deviations from interest rate parity are not closely related to monetary policy shocks, as recently hypothesized. Further, results suggest that inserting explicit interest rate parity shocks into a NOEM model may be more helpful in explaining movements in the current account than the exchange rate.

Paul R. Bergin

Department of Economics

University of California at Davis

One Shields Avenue

Davis, CA 95616

and NBER

pbergin@ucdavis.edu
\end{abstract}




\section{Introduction}

International macroeconomists increasingly have come to rely upon a class of models known as New Open Economy Macroeconomics (NOEM), characterized by microeconomic foundations in combination with nominal rigidities. While theoretical work in the NOEM literature has grown rapidly, there has been comparatively little work done on empirical dimensions. ${ }^{1}$ This has not been for a lack of interest, as it generally is agreed that if we are to trust these models for policy analysis, we should have some degree of confidence that they accurately reflect basic features of the economy. However, the macroeconomic models developed recently are sufficiently complex that estimating and testing them econometrically calls for new tools. This paper advances the NOEM literature in an empirical direction, estimating and testing a two country model by maximum likelihood methods. ${ }^{2}$ This estimation provides several results that could be useful in guiding future theoretical work.

The empirical record for earlier classes of macroeconomic models is very mixed. This is especially true with regard to the exchange rate and the current account, key variables for open economy macroeconomics. The current account dynamics of many countries have proved quite difficult to explain in terms of macroeconomic models using present value tests. ${ }^{3}$ And in a classic result, Meese and Rogoff (1983) showed that a range of macroeconomic models were unable to beat a random walk in forecasting the nominal exchange rate. Exchange rate movements have proved so problematic, that some recent research has recommended abandoning the attempt of explaining them in terms of macroeconomic models. (See Flood and Rose, 1999.)

As a result, it is becoming a familiar practice in NOEM studies to introduce exchange rate

\footnotetext{
1 In open economy work, see Bergin (2003), and Ghironi, Iscan and Rebucci (2003); in closed economy work, see Ireland (1997 and 2001), Kim (2000), Lubik and Schorfheide (2002), and Smets and Wouters (2002).

2 The current exercise goes beyond the initial empirical work in Bergin (2003) in important ways. In general terms, the model here is better suited to current questions raised in the theoretical literature, which are discussed in detail later in the paper. First, the model develops a means to allow multiple types of price stickiness to coexist, and so it can estimate the share of each type. Second, it uses a more general form of household preferences, to see if the estimated parameters support common assumptions in the theoretical literature regarding these preferences. Third, it does not assume that interest rate parity holds. The exercise also is improved on technical grounds, by ensuring stationarity of the wealth distribution and by allowing monetary policy authorities to respond to economic conditions. A final distinction is that instead of a small open economy, a two-country environment is modeled here, which is better suited to analyzing issues of the U.S. economy.

3 For example, see Sheffrin and Woo (1990), Ghosh (1995), and Bergin and Sheffrin (2000).
} 
movements in a manner other than macroeconomic fundamentals. This often is done by adding an extra term to the uncovered interest rate parity condition (UIP) in the macro model. ${ }^{4}$ Such a term is motivated by well-documented empirical evidence of strong deviations from UIP, ${ }^{5}$ and it can be interpreted in a number of different ways: Obstfeld and Rogoff (2002) derive such a term as a currency risk premium which is associated with monetary policy actions; Mark and Wu (1998) and Jeanne and Rose (2002) derive it as a reflection of noise traders and a distribution of exchange rate expectations.

In response to the controversy regarding macro models as explanations for the exchange rate and current account, this paper will pay special attention to these two variables. In particular, a maximum likelihood approach is adapted for estimating and evaluating a two country NOEM model. The U.S. is used as one of these countries, and an aggregate of the remaining G7 is used as the other country. The model is fit to five data series: the exchange rate, current account, output growth, inflation, and interest rate deviations between the two countries. Data is quarterly from 1973:1 to 2000:4.

The model shares many features common in NOEM models, including monopolistically competitive firms, sluggish price setting, capital accumulation subject to adjustment costs, and monetary policy in the form of interest rate setting rules. The procedure will estimate various deep parameters of interest in the theoretical literature. There will be five shocks to the system, including technology, monetary policy, consumption tastes, and the share of home bias in preferences; the fifth shock will be to the interest rate parity condition. The estimation procedure will also estimate the degree of correlation between the four structural shocks and the deviations from UIP.

Results indicate that the model as equipped above is able to explain the exchange rate and current account to some degree, in that it can beat a random walk in one-step ahead in-sample predictions. It is not able to beat a standard vector-autoregression in terms of predictions for the exchange rate and current account, although the overall fit of the model is superior to the VAR when the latter is appropriately penalized for its larger set of free parameters.

Parameter estimates are able to help address some current controversies in the theoretical NOEM

4 For examples, see McCallum and Nelson (1999 and 2000), Kollmann (2001 and 2002), and Jeanne and Rose (2002).

5 For a summary, see Lewis 1995. 
literature. One such controversy deals with the nature of price stickiness. While Betts and Devereux (2000) have argued that stickiness in the local currency of the buyer improves the model's ability to explain certain stylized facts regarding the exchange rate, Obstfeld and Rogoff (2000) have argued the opposite case. The model here permits both types of price stickiness to coexist, where the share is a parameter that can be estimated. Estimates indicate that a very high degree of local currency pricing is needed to successfully explain exchange rate movements in this data set. A second controversy regards the nature of household preferences, in particular, whether there is a unitary elasticity of substitution between home and foreign goods. This highly convenient assumption has become common practice in the theoretical literature, although it stands in contrast to empirical studies based on micro-level evidence. The estimates of this elasticity in the present paper offer empirical evidence from macro-level data which supports this common practice in the theoretical literature. Further, it has become common practice in NOEM models to impose stationarity on the net foreign asset position by specifying a country premium on interest rates, where this premium has a positive relationship to net foreign debt. The estimation exercise here offers an estimate for the parameter characterizing this positive relationship, which could prove useful as a basis for calibrations in future theoretical work.

Estimates also offer some new insights into the nature of deviations from uncovered interest rate parity (UIP). Results indicate that UIP deviations are not very closely related to monetary policy actions, contrary to an hypothesis in some theoretical NOEM work. However, these deviations are very highly correlated with shocks to marginal utility (taste shocks). Surprisingly, it appears that UIP shocks are even more important for explaining movements in the current account than the exchange rate. This may indicate that current account movements are determined in large part by financial shocks, which affect capital account flows, and thereby force current account adjustments through the balance of payments identity. This idea is quite different from the usual NOEM theory of the current account, as simply reflecting optimal saving and investment decisions, and it suggests a useful avenue for future research. 


\section{The Model}

\subsection{General Features}

Consider a two-country world, where the countries will be denoted home and foreign, and the population of home is fraction $n$ of the world total. Each country has a representative household and a representative firm, and each country has a distinct continuum of intermediate goods that it produces. Foreign variables will be indicated by an ${ }^{*}$, , and where necessary also by an $F$ subscript. All variables will be written in per capita terms. Steady state levels will be indicated by overbars.

\subsection{Market Structure}

Final goods in this economy $\left(Y_{t}\right)$ are produced by aggregating over a continuum of intermediate home goods indexed by $i \in[0,1]$ along with aggregating over a continuum of imported foreign goods indexed by $j \in[0,1]$. The aggregation technology for producing final goods is:

$$
\begin{aligned}
Y_{t} & =\left[\theta_{t}^{\frac{1}{\mu}} Y_{H t}^{\frac{\mu-1}{\mu}}+\left(1-\theta_{t}\right)^{\frac{1}{\mu}} Y_{F t}^{\frac{\mu-1}{\mu}}\right]^{\frac{\mu}{\mu-1}}, \text { where } \\
Y_{H t} & =\left(\int_{0}^{1} y_{H t}(i)^{\frac{1}{1+\nu}} d i\right)^{1+\nu} \\
Y_{F t} & =\left(\int_{0}^{1} y_{F t}(j)^{\frac{1}{1+\nu}} d j\right)^{1+\nu} .
\end{aligned}
$$

Here $Y_{H t}$ represents an aggregate of the home goods sold in the small open economy, and $Y_{F t}$ is an aggregate of the imported foreign goods, where lower case counterparts with indexes represent outputs of the individual firms. Note that the share parameter, $\theta_{t}$, is subject to stochastic shocks.

Final goods producers behave competitively, maximizing profit each period:

$$
\pi_{1 t}=\max P_{t} Y_{t}-P_{H t} Y_{H t}-P_{F t} Y_{F t},
$$

where $P_{t}$ is the overall price index of the final good, $P_{H t}$ is the price index of home goods, and $P_{F t}$ is the price index of foreign goods, all denominated in the home currency. It is assumed that fraction $\eta$ of firms (indexed $i=0, \ldots \eta$ ) exhibit local currency pricing, that is, they set the price of goods in the currency of the buyer. It is assumed that the remaining fraction $1-\eta$ of firms (indexed $i=\eta, \ldots 1$ ) 
exhibit producer currency pricing, that is, they set the price of goods in their own the currency.

The price indexes may be defined:

$$
\begin{aligned}
P_{t} & =\left[\theta_{t} P_{H t}^{1-\mu}+\left(1-\theta_{t}\right) P_{F t}^{1-\mu}\right]^{\frac{1}{1-\mu}}, \text { where } \\
P_{H t} & =\left(\int_{0}^{\eta} p_{H t}(i)^{-\frac{1}{\nu}} d i+\int_{\eta}^{1} p_{H t}(i)^{-\frac{1}{\nu}} d i\right)^{-\nu} \\
P_{F t} & =\left(\int_{0}^{\eta} p_{F t}(j)^{-\frac{1}{\nu}} d j+\int_{\eta}^{1} s p_{F t}(j)^{-\frac{1}{\nu}} d j\right)^{-\nu},
\end{aligned}
$$

and where lower case counterparts again represent the prices set by individual firms. The nominal exchange rate $\left(s_{t}\right)$ is the home currency price of one unit of the world currency. And the price index of home exports may be expressed:

$$
P_{H t}^{*}=\left(\int_{0}^{\eta} p_{H t}^{*}(j)^{-\frac{1}{\nu}} d j+\int_{\eta}^{1} \frac{1}{s_{t}} p_{H t}^{*}(j)^{-\frac{1}{\nu}} d j\right)^{-\nu} .
$$

Given the aggregation functions above, demand will be allocated between home and foreign goods according to:

$$
\begin{aligned}
& Y_{H t}=\theta_{t} Y_{t}\left(P_{t} / P_{H t}\right)^{\mu} \\
& Y_{F t}=\left(1-\theta_{t}\right) Y_{t}\left(P_{t} / P_{F t}\right)^{\mu},
\end{aligned}
$$

with demands for individual goods:

$$
\begin{aligned}
& y_{H t}(i)=Y_{H t}\left(p_{H t}(i) / P_{H t}\right)^{-(1+\nu) / \nu} \\
& y_{F t}(j)=Y_{F t}\left(p_{F t}(j) / P_{F t}\right)^{-(1+\nu) / \nu} \text { for } j=0, \ldots, \eta \\
& y_{F t}(j)=Y_{F t}\left(s_{t} p_{F t}(j) / P_{F t}\right)^{-(1+\nu) / \nu} \text { for } j=\eta, \ldots, 1 .
\end{aligned}
$$

Analogous conditions apply to the foreign country.

\subsection{Firm Behavior}

The firms rent capital $\left(K_{t}\right)$ at the real rental rate $r_{t}$, and hire labor $\left(L_{t}\right)$ at the nominal wage rate $W_{t}$. It is assumed that it is costly to reset prices because of quadratic menu costs. The problem for the local 
currency pricing $(i=0, \ldots \eta)$ firms may be summarized:

$$
\begin{gathered}
\max E_{0} \sum_{t=0}^{\infty} \rho_{t, t+n} \pi_{H t}(i) \\
\text { where } \pi_{H t}(i)=p_{H t}(i) y_{H t}(i)+s_{t} p_{H t}^{*}(i)\left(\frac{1-n}{n}\right) y_{H t}^{*}(i)-P_{t} r_{t} K_{t-1}(i) \\
-W_{t} L_{t}(i)-P_{t} A C_{H t}(i)-s_{t} P_{t} A C_{H t}^{*}(i) \\
\text { s.t. } A C_{H t}(i)=\frac{\psi_{P}}{2} \frac{\left(p_{H t}(i)-p_{H t-1}(i)\right)^{2}}{P_{t} p_{H t-1}(i)} y_{H t}(i) \\
\qquad C_{H t}^{*}(i)=\frac{\psi_{P}}{2} \frac{\left(p_{H t}^{*}(i)-p_{H t-1}^{*}(i)\right)^{2}}{P_{t} p_{H t-1}^{*}(i)}\left(\frac{1-n}{n}\right) y_{H t}^{*}(i) \\
z(i)_{t}=A_{t} K_{t-1}(i)^{\alpha} L_{t}(i)^{1-\alpha} \\
z(i)_{t}=y_{H t}(i)+\left(\frac{1-n}{n}\right) y_{H t}^{*}(i),
\end{gathered}
$$

and subject to the demand functions for $y_{H t}(i)$ and $y_{H t}^{*}(i)$ above. Here $A_{t}$ represents technology common to all production firms in the country, and it is subject to shocks. Lastly, $\rho_{t, t+n}$ is the pricing kernel used to value random date $t+n$ payoffs. Since firms are assumed to be owned by the representative household, it is assumed that firms value future payoffs according to the household's intertemporal marginal rate of substitution in consumption, so $\rho_{t, t+n}=\beta^{n} U_{C, t+n}^{\prime} / U_{C, t}^{\prime}$, where $U_{C, t+n}^{\prime}$ is the household's marginal utility of consumption in period $t+n$. The problem for the producer currency pricing firms $(i=\eta \ldots 1)$ is identical, except that $p_{H t}^{*}(i)$ is in units of home currency and equation (15) is replaced by:

$$
\begin{aligned}
\pi_{H t}(i)= & p_{H t}(i) y_{H t}(i)+p_{H t}^{*}(i)\left(\frac{1-n}{n}\right) y_{H t}^{*}(i)-P_{t} r_{t-1} K_{t-1}(i) \\
& -W_{t} L_{t}(i)-P_{t} A C_{H t}(i)-P_{t} A C_{H t}^{*}(i) .
\end{aligned}
$$

This problem implies an optimal trade-off between capital and labor inputs that depend on the relative cost of each:

$$
P_{t} r_{t} K_{t-1}(i)=\frac{\alpha}{1-\alpha} W_{t} L_{t}(i) .
$$

The optimal price setting rule for domestic sales of all home firms $(i=0, \ldots, 1)$ is:

$$
\begin{aligned}
& \frac{1+\nu}{\nu}\left(\frac{P_{t} r_{t}}{P_{H t} \alpha A_{t}\left(L_{t}(i) / K_{t-1}(i)\right)^{(1-\alpha)}}+\frac{\psi_{P}}{2} \frac{\left(p_{H t}(i)-p_{H t-1}(i)\right)^{2}}{P_{H t} p_{H t-1}(i)}-\frac{p_{H t}(i)}{P_{H t}}\right)\left(\frac{Y_{H t}}{y_{H t}(i)}\right)\left(\frac{p_{H t}(i)}{P_{H t}}\right)^{-\left(\frac{1+2 \nu}{\nu}\right)} \\
& +\frac{\psi_{P}}{2} E_{t}\left[\frac{\rho_{t, t+i+1}}{\rho_{t, t+i}}\left(\frac{p_{H t+1}^{2}(i)}{p_{H t}^{2}(i)}-1\right) \frac{y_{H t+1}(i)}{y_{H t}(i)}\right]-\psi_{P}\left(\frac{p_{H t}(i)}{p_{H t-1}(i)}-1\right)+1=0 .
\end{aligned}
$$


The optimal price setting rule for exports for local currency pricing firms $(i=0, \ldots, \eta)$ is:

$$
\begin{aligned}
& \frac{1+\nu}{\nu}\left(\frac{P_{t} r_{t}}{s_{t} P_{H t}^{*} \alpha A_{t}\left(L_{t}(i) / K_{t-1}(i)\right)^{(1-\alpha)}}+\frac{\psi_{P}}{2} \frac{\left(p_{H t}^{*}(i)-p_{H t-1}^{*}(i)\right)^{2}}{P_{H t}^{*} p_{H t-1}^{*}(i)}-\frac{p_{H t}^{*}(i)}{P_{H t}^{*}}\right)\left(\frac{Y_{H t}^{*}}{y_{H t}^{*}(i)}\right)\left(\frac{p_{H t}^{*}(i)}{P_{H t}^{*}}\right)^{-\left(\frac{1+2 \nu}{\nu}\right)} \\
& +\frac{\psi_{P}}{2} E_{t}\left[\frac{\rho_{t, t+i+1}}{\rho_{t, t+i}}\left(\frac{p_{H+t+1}^{* 2}(i)}{p_{H t}^{* 2}(i)}-1\right) \frac{s_{t+1}}{s_{t}} \frac{y_{H t+1}^{*}(i)}{y_{H t}^{*}(i)}\right]-\psi_{P}\left(\frac{p_{H t}^{*}(i)}{p_{H t-1}^{*}(i)}-1\right)+1=0,
\end{aligned}
$$

and the optimal price for exports by producer currency pricing firms $(i=\eta, \ldots, 1)$ is:

$$
\begin{aligned}
& \frac{1+\nu}{\nu}\left(\frac{P_{t} r_{t-1}}{s_{t} P_{H t}^{*} \alpha A_{t}\left(L_{t}(i) / K_{t-1}(i)\right)^{(1-\alpha)}}+\frac{\psi_{P}}{2} \frac{\left(p_{H t}^{*}(i)-p_{H t-1}^{*}(i)\right)^{2}}{s_{t} P_{H t}^{*} p_{H t-1}^{*}(i)}-\frac{p_{H t}^{*}(i)}{s_{t} P_{H t}^{*}}\right)\left(\frac{Y_{H t}^{*}}{y_{H t}^{*}(i)}\right)\left(\frac{p_{H t}^{*}(i)}{s_{t} P_{H t}^{*}}\right)^{-\left(\frac{1+2 \nu}{\nu}\right)} \\
& +\frac{\psi_{P}}{2} E_{t}\left[\frac{\rho_{t, t+i+1}}{\rho_{t, t+i}}\left(\frac{p_{H t+1}^{*}(i)}{p_{H t}^{* 2}(i)}-1\right) \frac{y_{H t+1}^{*}(i)}{y_{H t}^{*}(i)}\right]-\psi_{P}\left(\frac{p_{H t}^{*}(i)}{p_{H t-1}^{*}(i)}-1\right)+1=0 .
\end{aligned}
$$

\subsection{Household behavior}

The household derives utility from consumption $\left(C_{t}\right)$, and supplying labor $\left(L_{t}\right)$ lowers utility. For simplicity, real money balances $\left(M_{t} / P_{t}\right)$ are also introduced in the utility function, where $P_{t}$ is the overall price level. The household discounts future utility at the rate of time preference $\beta$. Preferences are additively separable in these three arguments, and preferences for consumption are subject to preference shocks $\left(\tau_{t}\right)$.

Households derive income by selling their labor at the nominal wage rate $\left(W_{t}\right)$, renting capital to firms at the real rental rate $\left(r_{t}\right)$, receiving real profits from the two types of firms $\left(\pi_{1 t}\right.$ and $\left.\pi_{2 t}\right)$, and from government transfers $\left(T_{t}\right)$. In addition to money, households can hold two types of noncontingent bonds, one denominated in home currency $\left(B_{t}\right)$ paying return $i_{t}$, and the other denominated in foreign currency $\left(-B_{t}^{*}\right)$ paying return $i_{t}^{*}$. Investment $\left(I_{t}\right)$ in new capital $\left(K_{t}\right)$ involves a quadratic adjustment cost and a constant rate of depreciation $(\delta)$.

The optimization problem faced by the household may be expressed:

$$
\begin{aligned}
& \max E_{0} \sum_{t=0}^{\infty} \beta^{t} U\left(C_{t}, \frac{M_{t}}{P_{t}}, L_{t}\right) \\
\text { s.t. } C A_{t}= & \frac{B_{t}-B_{t-1}}{P_{t}}-\frac{s_{t}\left(B_{t}^{*}-B_{t-1}^{*}\right)}{P_{t}} \\
\text { where } C A_{t} & \equiv \frac{W_{t}}{P_{t}} L_{t}+r_{t} K_{t-1}+\int_{0}^{1} \pi_{H t}(i) d i+T_{t}+i_{t-1} B_{t-1}-s_{t} i_{t-1}^{*} B_{t-1}^{*}
\end{aligned}
$$




$$
\begin{aligned}
& -C_{t}-I_{t}-A C_{I t}-\left(\frac{M_{t}}{P_{t}}-\frac{M_{t-1}}{P_{t}}\right) \\
U\left(C_{t}, L_{t}\right)= & \frac{\tau_{t}}{1-\sigma_{1}}\left(C_{t}\right)^{1-\sigma_{1}}+\frac{1}{1-\sigma_{2}}\left(\frac{M_{t}}{P_{t}}\right)^{1-\sigma_{2}}-\frac{\sigma_{3}}{1+\sigma_{3}}\left(L_{t}\right)^{\frac{1+\sigma_{3}}{\sigma_{3}}} \\
I_{t}= & K_{t}-\left(1-\delta_{t}\right) K_{t-1} \\
A C_{I t} & =\frac{\psi_{I}}{2} \frac{\left(K_{t}-K_{t-1}\right)^{2}}{K_{t-1}} \\
\text { where } \sigma_{i} & >0 \text { for } i=1 \ldots 3, \psi_{I} \geq 0 .
\end{aligned}
$$

The household problem implies the following optimality conditions. First, households will smooth consumption across time periods according to:

$$
\tau_{t} C_{t}^{-\sigma_{1}}=\beta\left(1+i_{t}\right) E_{t}\left[\tau_{t+1} C_{t+1}^{-\sigma_{1}}\left(\frac{P_{t}}{P_{t+1}}\right)\right] .
$$

Households prefer expected marginal utilities to be constant across time periods, unless a rate of return on saving exceeding their time preference induces them to lower consumption today relative to the future. Second, household money demand will be:

$$
\left(\frac{M_{t}}{P_{t}}\right)^{-\sigma_{2}}=\tau_{t} C_{t}^{-\sigma_{1}} \frac{i_{t}}{1+i_{t}}
$$

Third, optimal portfolio choices imply the interest rate parity (UIP) condition:

$$
E_{t}\left[\frac{U_{C t+1}^{\prime}}{U_{C t}^{\prime}} \frac{s_{t+1}}{s_{t}} \frac{P_{t}}{P_{t+1}}\left(1+i_{t}^{*}\right)\right]=E_{t}\left[\frac{U_{C t+1}^{\prime}}{U_{C t}^{\prime}} \frac{P_{t}}{P_{t+1}}(1+i)_{t}\right] .
$$

Since the model equations will be used only as linear approximations, the UIP condition would appear in the following simplified form:

$$
(1-\beta)\left(\widetilde{i}_{t}-\widetilde{i}_{t}^{*}\right)=E_{t}\left(\widetilde{s}_{t+1}-\widetilde{s}_{t}\right) .
$$

where tildes here indicate percent deviations from steady state. This approximation omits the nonlinear terms involving marginal utilities and prices, which represent risk premium terms and Jensen's inequality. It is well known that this form of the UIP condition is strongly rejected by the data (Lewis 1995), so we will generalize this expression by adding to the right hand side of (33) above a "risk premium term" as follows:

$$
R P_{t}=-\Psi_{B}\left(\frac{B_{t}-s_{t} B_{t}^{*}}{P_{t} Y_{t}}\right)+\xi_{t}
$$


One component of this term is a mean-zero disturbance, $\xi_{t}$, aimed at capturing time-varying deviations from UIP. Such a term is a common device in macro models (see McCallum and Nelson (1999 and 2000), Kollmann (2001 and 2002), and Jeanne and Rose (2002).) There are a number of ways to interpret this term. McCallum and Nelson (1999 and 2000) interpret it as a representation of the time-varying risk premium omitted by linearization. Obstfeld and Rogoff (2002) show theoretically how this risk premium could vary over time with changes in the properties of monetary policy actions. Mark and Wu (1998) and Jeanne and Rose (2002) derive it as a reflection of noise traders and a distribution of exchange rate expectations. A second component of the $R P_{t}$ term will be a function of the debt of a country. This can be motivated as a risk premium as well, where lenders demand a higher rate of return on a country with a large debt to compensate for perceived default risk. The primary motivation for including this term here is as a device to remove an element of nonstationarity in the model, as has been demonstrated in Schmitt-Grohe and Uribe (2003). Given the incomplete asset markets, shocks can lead to permanent wealth reallocations that would induce nonstationarity and prevent computation of the second moments used in estimation. Introducing the risk premium term as a function of debts forces wealth allocations in the long run to return to their initial distribution. ${ }^{6}$

As a fourth optimality condition, households supply labor to the point that the marginal disutility of labor equals its marginal product: ${ }^{7}$

$$
L_{t}^{\frac{1}{\sigma_{3}}}=\frac{W_{t}}{P_{t}} \tau_{t}^{1-\sigma_{1}} C_{t}^{-\sigma_{1}}
$$

Finally, capital accumulation is set to equate the costs and expected benefits:

$$
\left(1+\frac{\psi_{I}\left(K_{t}-K_{t-1}\right)}{K_{t-1}}\right)=\beta E_{t}\left[\left(\frac{\tau_{t+1}^{1-\sigma_{1}} C_{t+1}^{-\sigma_{1}}}{\tau_{t}^{1-\sigma_{1}} C_{t}^{-\sigma_{1}}}\right)\left(r_{t+1}+(1-\delta)+\frac{\Psi_{I}}{2}\left(\frac{K_{t+1}^{2}-K_{t}^{2}}{K_{t}^{2}}\right)\right)\right] .
$$

The cost, on the left side, is the gross return if the funds instead had been used to purchase bonds; and the benefits on the right include the return from rental of the capital plus the resale value after depreciation, and the fact that a larger capital stock lowers the expected adjustment cost of further

\footnotetext{
$6 \quad$ A similar UIP condition is implied by the foreign agent optimization, and these two conditions will be identical when linearized. As a result, a bond allocation rule could be created to solve for $B$ and $B^{*}$ separately. Instead, we here solve for $B-B^{*}$, thereby eliminating the need for the bond allocation rule.

7 Wage rigidities are not included in this model because past empirical work in Bergin (2003) showed that they tend to be extraneous in a model of this type when fit to these data series.
} 
accumulation in the subsequent period.

Write the resource constraint (define final goods demand):

$$
Y_{t}=C_{t}+I_{t}+G_{t}+A C_{I t}+\int_{0}^{1} A C_{H t}(i) d i+\int_{0}^{1} A C_{H t}^{*}(i) d i
$$

The goods market clearing condition is:

$$
n Y_{H t}+(1-n) Y_{H t}^{*}=n Z_{t}
$$

Define the trade balance in per capita terms $(X)$ :

$$
X_{t}=\left(\frac{1-n}{n}\right) \frac{s_{t} P_{H t}^{*}}{P_{t}} Y_{H t}^{*}-\frac{P_{F t}}{P_{t}} Y_{F t}
$$

To keep the number of state variables to a minimum, we abstract from government issue of debt here. Given that the model has no features to break Ricardian equivalence, this simplification has no impact on the results. The simple government budget constraint is:

$$
T_{t}-G=\frac{1}{P_{t}}\left(M_{t}-M_{t-1}\right) .
$$

Combine the budget constraints of the household, firm, and government:

$$
\begin{aligned}
& P_{H t} Y_{H t}+s_{t} P_{H t}^{*}\left(\frac{1-n}{n}\right) Y_{H t}^{*}+i_{t-1} B_{t-1}+s_{t} i_{t-1}^{*} B_{t-1}^{*} \\
= & P_{t}\left(C_{t}+I_{t}+G_{t}+A C_{H t}+A C_{H t}^{*}\right)+\left(B_{t}-B_{t-1}\right)-s_{t}\left(B_{t}^{*}-B_{t-1}^{*}\right) .
\end{aligned}
$$

Use the resource constraint above to write this using $Y_{t}$, and then rewrite this in terms of home and imported goods:

$$
\begin{aligned}
& P_{H t} Y_{H t}+\left(\frac{1-n}{n}\right) s_{t} P_{H t}^{*} Y_{H t}^{*}-\left(P_{H t} Y_{H t}+P_{F t} Y_{F t}\right)+i_{t-1} B_{t-1}-s_{t} i_{t-1}^{*} B_{t-1}^{*} \\
= & \left(B_{t}-B_{t-1}\right)-s_{t}\left(B_{t}^{*}-B_{t-1}^{*}\right) .
\end{aligned}
$$

Use the definition of the trade balance to write the balance of payments condition:

$$
P_{t} X_{t}+i_{t-1} B_{t-1}-s_{t} i_{t-1}^{*} B_{t-1}^{*}=\left(B_{t}-B_{t-1}\right)-s_{t}\left(B_{t}^{*}-B_{t-1}^{*}\right)
$$

The monetary policy will be specified in terms of an interest rate targeting rule:

$$
i_{t}=\bar{i}+\left(\beta a_{1}\right)^{-1}\left(\frac{P_{t}}{P_{t-1}}\right)+a_{2}\left(\frac{Y_{t}}{\bar{Y}}\right)+a_{3}\left(\frac{s_{t}}{\bar{s}}\right)+\phi_{t},
$$


where $\phi_{t}$ is a monetary policy shock. ${ }^{8}$

The shocks may be specified:

$$
\begin{array}{ll}
\phi_{t} & =\rho_{\phi}\left(\phi_{t-1}\right)+\varepsilon_{\phi t} \\
\left(\log A_{t}-\log \bar{A}\right) & =\rho_{A}\left(\log A_{t-1}-\log \bar{A}\right)+\varepsilon_{A t} \\
\left(\log \theta_{t}-\log \bar{\theta}\right) & =\rho_{\theta}\left(\log \theta_{t-1}-\log \bar{\theta}\right)+\varepsilon_{\theta t} \\
\log \tau_{t} & =\rho_{\tau}\left(\log \tau_{t-1}\right)+\varepsilon_{\tau t} \\
\xi_{t} & =\rho_{\xi}\left(\xi_{t-1}\right)+\varepsilon_{\xi_{t} t} \\
& \quad\left[\varepsilon_{\phi t}, \varepsilon_{A t}, \varepsilon_{\theta t}, \varepsilon_{\tau t}, \varepsilon_{\xi t}\right]^{\prime \sim} N\left(0, \Sigma_{1}\right) .
\end{array}
$$

The equilibrium conditions all will be used in a form linearized around a deterministic steady state. Further, the variables will be written as country differences, home minus the foreign counterpart. This allows the dimensions of the data set and parameter space to be reduced, which is necessary to make the sizeable empirical exercise tractable. ${ }^{9}$ The appendix lists all equilibrium conditions of the model transformed in this way.

\section{Empirical Methods}

\subsection{Data}

Data for the U.S. will be used for the home country, and an aggregate of the remaining G7 will be used for the foreign country. The five series used will be the exchange rate and the current account, which are the primary variables of interest here, as well as the interest rate, output, and the price level. The interest rate was included to help identify monetary policy shocks, and output was included to help identify the technology shocks specified in the model. The price level is important for identifying the role of price stickiness in the model, which is an issue of interest in the literature. In addition, these three variables have been a common choice in early tests of how well macroeconomic models

\footnotetext{
8 More complex policy rules proved problematic for convergence of the estimation algorithm.

9 Note that this transformation will require the assumption that many of the deep behavioral parameters are the same for both countries in the model. But this simplification is common in the empirical macroeconomic literature (see Meese and Rogoff (1983)). Given that the foreign country here will represent an aggregate of the G-7 countries less the U.S., as is common practice, this means that we already are assuming that the parameters of six of the seven countries in the data set are the same. Note that this assumption does not need to be applied to the parameter representing monetary policy responses to the bilateral exchange rate; in this case the transformation implies that the parameter estimated instead is just the sum of home and foreign parameters. As a result, the model does allow for asymmetric responses by the two countries to the bilateral exchange rate.
} 
can explain exchange rates, as in Meese and Rogoff (1983).

All data are seasonally adjusted quarterly series at annual rates for the period 1973:1 to 2000:4, obtained from International Financial Statistics. The exchange rate for each country is measured as the bilateral rate with the U.S. dollar. The current account is measured as GNP less expenditure on consumption, investment, and government purchases. Output is measured as national GDP, the domestic price level as the CPI, and the interest rate as a treasury bill rate or something similar. ${ }^{10}$ Foreign aggregate variables are computed as a geometric weighted average, where time-varying weights are based on each country's share of total real GDP. Series other than the current account are logged. Because the steady state value of the current account in the theoretical model is necessarily zero, this variable cannot be expressed in the model in a form that represents deviations from steady state in $\log$ form. Instead the current account is scaled by taking it as a ratio to the mean level of output.

As a preliminary step, the data series are tested for unit roots. Table 1 shows the results. The seven series appear to be nonstationary in levels but stationary in first differences. This motivates the decision to fit the model to data in first differences. This is a common practice in the structural VAR studies to which we wish to compare our empirical results. ${ }^{11}$ The data will also be demeaned and transformed into country differences, home minus the foreign counterpart. The last transformation of course does not apply to the exchange rate or current account, but it means that the last three variables in the data set will be movements in interest rate differentials, differences in output growth rates, and differences in inflation rates.

\subsection{Econometric Methods}

The econometric methodology fits the linear approximation to the structural model, adapting a maximum likelihood algorithm developed in Leeper and Sims (1994) and extended in Kim (2000).

10 The treasury bill rate was used for the U.S., U.K., Canada, and France; the money market rate was used for Italy; and the call money rate was used for Germany and Japan.

11 See Ahmed (1993). 
The linearized model equations, as derived in the section above and transformed and listed in the appendix, can be expressed in autoregressive form as

$$
\begin{gathered}
y_{t}=A y_{t-1}+\varepsilon_{t} \\
\varepsilon_{t} \sim N(0, \Sigma)
\end{gathered}
$$

where $y$ is the18-element column vector of variables listed in the appendix. $A$ is a $18 x 18$ matrix, where each cell is a non-linear function of the structural parameters; $\varepsilon$ is a column vector, containing the five structural disturbances and where the remaining elements are zeros; and $\Sigma$ is the covariance matrix of these disturbances.

The model system may be rewritten in terms of first differences as follows:

$$
\begin{aligned}
& y_{t}^{*}=A y_{t-1}^{*}+\varepsilon_{t}-\varepsilon_{t-1} \\
& \text { where } y_{t}^{*}=y_{t}-y_{t-1} .
\end{aligned}
$$

This stochastic model implies a log likelihood function:

$$
L(\Pi)=-.5 \ln |\Omega|-.5 x^{\prime} \Omega^{-1} x
$$

where $x$ is the vector of the five variables on which we have data, over all periods stacked into a single vector, and $\Omega$ is the theoretical variance-covariance matrix of the variables in $x$. The appendix discusses the details of how $\Omega$ is computed as a function of the matrices $A$ and $\Sigma$. But note that each cell in $A$ is a nonlinear function of the structural parameters from the theoretical model. An algorithm is used to search for values of these structural parameters and for the elements of the symmetric positive-definite covariance matrix $\Sigma$, which will maximize the likelihood function. Note that taking first differences should not introduce the classic problem of "overdifferencing" here. The fact that differencing may introduce a moving average term is taken into consideration in equation (45) and hence the computation of $\Omega$ and the likelihood function, so a misspecified model is not being estimated.

A few parameters will not be estimated here, but instead are pinned down ahead of time. This is 
because the data set omits the relevant series for these parameters, like capital and labor, or because the data set in first differences is not very relevant for parameters pertaining to steady states. As a result, these parameters are pinned down at values common in the Real Business Cycle literature. In particular, the capital share in production $(\alpha)$ is set at 0.40 , the depreciation rate $(\delta)$ is set at 0.10 , the labor supply elasticity $\left(\frac{1}{\sigma_{3}}\right)$ is calibrated at unity, the steady state share of home intermediate goods in the home final goods aggregate $(\bar{\theta})$ is set at 0.80 , and the discount factor $(\beta)$ is set at 0.96 .

Some regions of the parameter space do not imply a well defined equilibrium within the model. These regions can be precluded by imposing boundaries on the parameters by functional transformations. For example the variances of shocks and the intertemporal elasticity are restricted to be positive. The monetary policy reaction to inflation is bounded below to rule out indeterminacy. Autoregressive coefficients on shock processes are also restricted to be greater than zero and less than unity. Finally, the covariances between shocks must be restricted so that the implied correlations lie between -1 and 1 .

\section{Results}

Table 2 shows the basic results from estimating the model. Regarding fit, the table reports the likelihood value as 1797.6, compared to 1823.8 for a standard unidentified vector autoregression (VAR) of the five variables in the data set. A likelihood ratio test cannot be used to compare the two, since the structural model is not nested in the VAR. ${ }^{12}$ However, a comparison can be made in terms of the Schwarz criterion, which penalizes the VAR for the fact it has 40 free parameters compared to the 24 of the structural model. By this comparison, the structural model performs better. The fit of the model can also be evaluated in terms of how well it can forecast the variables one period ahead. The table reports root mean squared errors, indicating that the structural model has larger forecast error for all five variables. It is interesting to note that the model comes closest for the exchange rate and the current account.

\footnotetext{
12 Given the unobserved variables in the structural model, it cannot be written as a first-order VAR in just the five observed
} variables. See Bergin (2003) for details. 
Perhaps a more fair comparison, given the VAR's extra parameters is a random walk model. One may recall the classic result of Meese and Rogoff (1983) that no macro model was able to beat a random walk in forecasting the exchange rate out of sample. Table 2 shows that the structural model here does beat a random walk in in-sample predictions for the exchange rate, as well as for the current account and the interest rate. Note that the predictions generated by this methodology are in sample, and hence are not directly comparable to those of Meese-Rogoff. ${ }^{13}$

The model also does quite well in terms of fitting unconditional moments, which is the typical measure of fit used in real business cycle exercises. This is a bit unfair here, given that the maximum likelihood estimation is trying to fit a set of hundreds of moments, not just a handful of arbitrary moments that researchers have in the past chosen to focus upon. Nevertheless, for the data as transformed here (in logged differences and demeaned), the variance of the exchange rate is 0.00290 in the data and 0.00293 in the model, the variance of the current account is $1.44 \times 10^{-5}$ in the data and $1.51 \times 10^{-5}$ in the model, and the covariance between the exchange rate and the current account is $6.52 \times 10^{-6}$ in the data and $6.19 \times 10^{-6}$ in the model.

The parameter estimates generally are reasonable and statistically significant. The elasticity of intertemporal substitution $\left(\frac{1}{\sigma_{1}}\right)$ is near unity. The interest elasticity of money demand implies an income elasticity of money demand $\left(\frac{\sigma_{1}}{\sigma_{2}}\right)$ which is a bit high, around 4 . The investment adjustment $\operatorname{cost}\left(\Psi_{I}\right)$ is high but not implausible, implying that if investment rises $1 \%$ above steady state, about $1.1 \%$ of this investment goes toward paying the adjustment cost. The adjustment cost on prices $\left(\Psi_{P}\right)$ is quite reasonable, indicating that after a money supply shock the half-life of price-level adjustments is about five quarters.

Some of the parameters estimated here deal directly with points of controversy in the theoretical New Open Economy Macro literature. One such controversy regards the functional form of consumer preferences. A common practice in the literature has been to assume Cobb-Douglas preferences between home and foreign goods, implying a unitary elasticity of substitution. This form has

\footnotetext{
13 Conducting out of sample tests here is problematic. To avoid the Lucas Critique, the model is specified in terms of "deep" parameters, which as a matter of principle should not be changed period by period. Further, estimation is sufficiently time-consuming that re-estimation for every period may not be practical.
} 
convenient risk-sharing properties in many NOEM models, which facilitate analytical solution. This assumption stands in contrast to studies based on micro-level evidence, which have tended to suggest higher elasticities around 5 (See Harrigan, 1993.) However, there has been a recent defense of a unit elasticity for macro-level data. One might imagine that there is less substitutability between home goods as an aggregate and foreign goods as an aggregate, which is the concept relevant for our macro modeling, than between home and foreign versions of an individual variety of good. (See Pesenti, 2002.) The estimate of the elasticity of substitution in the present model supports this hypothesis. Table 2 reports a level of $\mu$ quite close to unity; while it is significantly different from zero statistically, it is not significantly different from unity. This lends empirical support to the common practice which the theoretical literature has found so convenient.

Another controversy regards the choice of currency in which prices are sticky. Betts and Devereux (2000) argue that assuming prices are sticky in the currency of the buyer (local currency pricing) improves a model's ability to explain exchange rate behavior. On the other hand, Obstfeld and Rogoff (2000) argue in favor of prices sticky in the currency of the seller (producer currency pricing). As explained above, this model is set up to allow both types of price-setters to coexist, and the share of local currency pricing firms , $\eta$, is a parameter that can be estimated empirically. Table 2 shows that the estimate of this share presses up against the upper bound of unity. ${ }^{14}$ This indicates strong support for the use of local currency pricing in NOEM models, in as much as this provides a useful way of explaining the macroeconomic times series examined here.

Table 2 also provides an estimate for $\psi_{B}$, which characterizes the sensitivity of a country interest rate premium to changes in net foreign assets. The estimated value of 0.00384 implies that when a G7 country runs a net foreign debt that is $20 \%$ of GDP (a relevant value for the U.S.), its domestic interest rate would rise by 7.68 basis points. This is very close to the calibrated value used in Nason and Rogers (2003) based on empirical work for Canada, but somewhat lower than the value estimated

14 The standard error appears very small here, because the estimation algorithm estimates a functional transformation of this parameter, with a range over $(-\infty, \infty)$ rather than the range of $(0,1)$ of the original parameter. A large section of the range over which the algorithm searches is mapped into a narrow range of the reported parameter near its upper bound of unity. The delta method thus reports small standard errors in terms of the original parameter value. 
from panel and cross-sectional regressions in Lane and Milesi-Ferretti (2002) ${ }^{15}$. It is hoped that this estimate might prove useful as a basis for calibrations in future theoretical work.

Finally, the table also lists parameters in the monetary policy reaction function. Since the estimate of $a_{1}$ is close to its boundary of unity, the monetary response to inflation is close to its lower bound of $\left(\frac{1}{\beta a_{1}}\right)$, imposed to ensure a unique equilibrium. This suggests that the model might fit the data better if we permitted it to explore regions of the parameter space that involved indeterminacy, as has been suggested by Lubik and Schorfheide (2002). The response to output $\left(a_{2}\right)$ is near zero, indicating little evidence of active output stabilization. The statistically significant estimate of $a_{3}$ indicates some systematic response to stabilize exchange rates by some countries. ${ }^{16}$

Table 2 is informative also about the nature of structural shocks. Of particular interest are the correlations at the bottom of the table. Obstfeld and Rogoff (2002) have posited a NOEM model in which monetary policy accounts for deviations from interest rate parity. But the estimated model here indicates that the deviations from interest rate parity we observe in the data have fairly little to do with any monetary policy innovation or with technology shocks. However, there is a high degree of negative correlation with the taste shocks defined in this model (correlation coefficient of -0.86). This result is interesting, as the taste shock $(\tau)$ directly affects marginal utility, which is an important element in the risk premium term dropped from the UIP condition due to linearization, as discussed above. Additional interpretation of this relationship between taste shocks and interests rate parity deviations will follow below. Estimates of shock variances do not lend themselves to direct interpretation and are not shown in the table, but these will be interpreted in the form of variance decompositions to follow shortly. The shock autocorrelations indicate a fairly high degree of persistence in all the shocks. Fortunately, none presses up against the boundary of unity, required to maintain stationarity of the theoretical system.

Impulse responses offer a greater sense of what these parameters imply for the dynamics of the economy. Figure 1 shows the impulse responses of the five data variables to a one-standard deviation

$15 \quad$ Lane and Milesi-Ferretti (2001) estimate a value of 0.0107 from cross-sectional regressions and a value of 0.0254 from panels. Nason and Rogers (2003) use a value of 0.0035.

16 Recall that in the transformed model $a_{3}$ is the sum of home and foreign responses to the bilateral exchange rate. 
shock to the monetary policy rule. As the interest rate rises, this induces an immediate fall in output and a gradual fall in the price level. ${ }^{17}$ The monetary contraction induces a significant exchange rate appreciation, in which the exchange rate overshoots. It also involves a small degree of worsening in the current account.

Figure 2 illustrates an interest rate parity shock in the context of this model. Such a shock permits the home interest rate to rise relative to the foreign rate, even though the value of the domestic currency is appreciating over time, as is often observed empirically. The shock may be understood as a type of portfolio shift away from home assets, such that an excess return is required to make households willing to hold home bonds in equilibrium. While this shock is often used as a shorthand way of introducing exchange rate fluctuations in a NOEM model, it is interesting to note that this shock implies movements in a variety of variables, not just the exchange rate. In particular, the interest rate moves substantially here, and there is also a sizeable response in the current account.

Given the apparent relationship between the interest parity shock and the taste shock, figure 3 is included to show the impulse response to the latter. It implies a case where the current account moves in very much the same way as in figure 2 for an interest parity shock, but the exchange rate moves in the opposite direction. If these two shocks indeed are highly negatively correlated, the combination of the two would imply a large change in the exchange rate, while any effect on the current account is substantially canceled out. This observation will be useful in analysis below.

A natural question is how important are the interest parity shocks to these results? In particular, is the model able to explain the exchange rate simply because it can invoke the UIP shock to drive the exchange rate as needed to match the data? To address this question one can consider variance decompositions, which show what fraction of the forecast error variance for each variable is explained by each of the shocks at various time horizons. This analysis is complicated somewhat by the fact that UIP deviations are allowed to be correlated here with the four structural shocks. Recall that this choice was made because UIP deviations do not strictly arise from the structural model, and because

\footnotetext{
17 The hump-shaped response of the interest rate comes from the fact that the exchange rate begins to depreciate after the
} initial period of overshooting, and the policy rule responds to this by increasing the interest rate a bit further. 
we wished to gather information that might help us interpret these UIP deviations and offer guidance to future modelers. As a result, to disentangle the various contributions of these shocks, one must take steps to orthogonalize them. It might seem that a natural approach would be to re-estimate the model, requiring the shocks to be orthogonal. However, this estimation produced a likelihood value of only 1755.737. This version of the model may be regarded as nested in the benchmark case shown in Table 2, with the addition of four restrictions requiring the correlations between shocks to be zero. As a nested comparison, a likelihood ratio test can be used, where twice the difference of the likelihood values follows a chi-squared distribution with 4 degrees of freedom. The p-value of such a comparison is zero, indicating we should reject the restrictions. Because the model that assumes orthogonal shocks is strongly rejected by the data, I will continue to utilize the model that permits them to be correlated.

As a result, we must take a stand on how to disentangle the joint contribution of the UIP and other shocks. Table 3 shows variance decompositions which orthogonalize the UIP shock by attributing any joint contribution shared between the UIP and another shock to that other shock. ${ }^{18}$ The table shows that the independent part of UIP shocks explains only about $1 \%$ of exchange rate movements in this model. This suggests that the UIP shock is not being used here to drive the exchange rate and artificially boost the model fit. Instead a bit more than half of the exchange rate movements appear to be driven by monetary policy shocks. This result is comparable to that found in past studies. Eichenbaum and Evans (1995) found variance decompositions between 18\% and $43 \%$ using standard VAR techniques. Rogers (1999) found between 19\% and 60\%. Faust and Rogers (2000) found estimates ranging from the single digits to around 50\% using a structural VAR that considered a wide range of identification assumptions. Ahmed et al (1993) found almost no role for monetary shocks in a structural VAR using long-run identification restrictions. In our estimation, taste shocks also have some importance, explaining about $25 \%$ of exchange rate movements.

\footnotetext{
18 Mechanically this is accomplished by a Cholesky decomposition, where the UIP shock is ordered last. Note that the ordering of the other four shocks is inconsequential, since these structural shocks are orthogonal to each other already. Note also that this orthogonalization differs from the standard VAR practice, as we are ordering shocks not variables. There is no need to use the ordering to achieve identification of shocks, since the structure of the model has already provided sufficient restrictions for identification.
} 
In contrast for the current account, Table 3 shows that a surprisingly large role is played by the UIP shock. Nearly two-thirds of current account movements are attributable to these shocks, which raises an interesting possibility. These UIP shocks represent portfolio shifts in the asset market between countries, which naturally affect a country's capital account. These shocks to the capital account then should affect the current account through the balance of payments identity. The model seems to be suggesting that attempts in the New Open Economy literature to explain current account movements in terms of optimal intertemporal saving decisions may be misplaced. Rather, the current account could be driven substantially by financial shocks affecting the capital account side of the balance of payments, which then forces adjustment in saving and investment on the current account side. This conjecture should be pursued in the future in the NOEM literature.

For completeness, Table 4 shows variance decompositions with the opposite method of orthogonalization, where comovements in the UIP shock with other shocks is awarded instead to the UIP shock. By this accounting, the role of UIP shocks in driving exchange rates goes up somewhat, but it still explains less than a quarter of exchange rate movements at its maximum. Monetary policy shocks still are the main explanation and account for about half of the forecast error variance. Given that it is the coincidence of UIP deviations with other shocks that affects the variance decomposition, one may conclude that UIP shocks have their greatest usefulness in explaining exchange rate movements not as an independent factor, but as a way of modifying the effect of other shocks. For example, recall from above that taste and UIP shocks are highly negatively correlated. Recall also from the discussion of impulse responses that the combination of a UIP and a negative taste shock implies a large movement in the exchange rate with a net effect on the current account that is near zero. The estimated model thus suggests a channel for explaining the "relative price puzzle" and the "exchange rate disconnect puzzle" noted in several papers (see Flood and Rose (1999), Duarte and Stockman (2001), and Devereux and Engel (2002)). That is, the structural model has found one way to account for the fact that volatility of the exchange rate tends to be high relative to quantity variables like the current account, where large movements in the former have little impact on the latter. ${ }^{19}$ Future 19 This conclusion is supported by results in Table 4 regarding variance decompositions of the current account. The 
theoretical work may wish to pursue this suggestion, by looking for sources of interest rate parity deviations that involve shifts in marginal utilities.

\section{Conclusions}

This paper has advanced the New Open Economy Macroeconomic literature in an empirical direction, fitting a two-country model by maximum-likelihood to data from the U.S. and an aggregate of the remaining G7. The model fits reasonably well, in that it is able to beat a random walk model for in-sample predictions of the exchange rate and current account, variables of key interest to open economy macroeconomists. The estimated model facilitates empirical answers to a number of interesting questions raised recently in the theoretical literature. For example, it gives empirical support to the assumption of local currency pricing by firms, as well as to the common simplifying assumption of a unitary elasticity of substitution between home and foreign goods. It also provides an estimate for how a country interest rate premium responds to changes in net foreign debt positions, an estimate which might prove useful as a basis for calibrations of future theoretical models. In addition, the exercise indicates that deviations from interest rate parity do not seem to be closely related to monetary policy, as has been hypothesized in recent theory, but that these deviations do seem to be related to shifts in marginal utilities of consumption. Further, the model indicates that such interest rate parity shocks are not especially helpful as independent explanations for exchange rate movements observed in the data. But on the other hand, these shocks are helpful in explaining movements in the current account. It is hoped that this study may prove helpful for discriminating between alternative theoretical models currently being proposed, and for suggesting productive avenues for future theoretical research.

respective roles of the taste and IRP shocks switch from those in Table 3. This clearly comes from the fact that there is a high negative correlation between the two shocks as described above. Whenever the effects of the two shocks are considered jointly there is no net effect on the current account, but the portion of either shock taken alone has a strong effect on the current account. This underscores the fact that the two shocks are closely related to each other. 


\section{Acknowledgements}

I thank participants in the 2003 AEA meetings and the CEPR International Capital Markets conference in Rome 2003 for helpful comments. I thank Ivan Tchakarov for excellent research assistance. This material is based upon work supported by the National Science Foundation under Grant No. 0109006. Any opinions, findings, and conclusions or recommendations expressed in this material are those of the author and do not necessarily reflect the views of the National Science Foundation 


\section{Appendix}

\subsection{List of Equilibrium Conditions}

These equations are used in liearized form, expressed as differences between the home country variables and foreign country counterparts. The system may be written in the following 18 variables: $c_{t}-c_{t}^{*}, l_{t}-l_{t}^{*}, y_{t}-y_{t}^{*}, p_{t}-p_{t}^{*}, w_{t}-w_{t}^{*}, p_{F t}-p_{H t}^{*}, p_{H t}-p_{F t}^{*}, y_{H t}-y_{F t}^{*}, y_{F t}-y_{H t}^{*}, z_{H t}-z_{H t}^{*}$, $i_{t}-i_{t}^{*}, k_{t}-k_{t}^{*}, r_{t}-r_{t}^{*}, B_{t}-B_{t}^{*}, M_{t}-M_{t}^{*}, s_{t}, c a_{t}, x_{t}$. Numbered below are the 18 linearized conditions that determine these sequences.Country size is $n$.

Linearized home consumption Euler:

$$
\sigma_{1} c_{t}-\tau_{t}=\sigma_{1} E_{t}\left(c_{t+1}\right)-E_{t}\left(\tau_{t+1}\right)+E_{t}\left[P_{t+1}\right]-P_{t}-(1-\beta) i_{t}
$$

together with the foreign counterpart:

$$
\sigma_{1} c_{t}^{*}-\tau_{t}^{*}=\sigma_{1} E_{t}\left(c_{t+1}^{*}\right)-E_{t}\left(\tau_{t+1}^{*}\right)+E_{t}\left[P_{t+1}^{*}\right]-P_{t}^{*}-(1-\beta) i_{t}^{*}
$$

to form:

$$
\begin{aligned}
\sigma_{1}\left(c_{t}-c_{t}^{*}\right)-\left(\tau_{t}-\tau_{t}^{*}\right)= & \sigma_{1} E_{t}\left(c_{t+1}-c_{t+1}^{*}\right)-E_{t}\left(\tau_{t+1}-\tau_{t+1}^{*}\right) \\
& +E_{t}\left[P_{t+1}-P_{t+1}^{*}\right]-\left(P_{t}-P_{t}^{*}\right)-(1-\beta)\left(i_{t}-i_{t}^{*}\right) .
\end{aligned}
$$

Money demand:

$$
\sigma_{1} c_{t}+\sigma_{2} p_{t}-\sigma_{2} m_{t}-\tau_{t}-\frac{\beta^{2}}{1-\beta} i_{t}=0
$$

combined with foreign:

$$
\begin{aligned}
& \sigma_{1}\left(c_{t}-c_{t}^{*}\right)+\sigma_{2}\left(p_{t}-p_{t}^{*}\right)-\sigma_{2}\left(m_{t}-m_{t}^{*}\right) \\
& -\left(\tau_{t}-\tau_{t}^{*}\right)-\frac{\beta^{2}}{1-\beta}\left(i_{t}-i_{t}^{*}\right)=0 .
\end{aligned}
$$

Labor supply:

$$
\frac{1}{\sigma_{3}}\left(l_{t}-l_{t}^{*}\right)=\left(w_{t}-w_{t}^{*}\right)-\sigma_{1}\left(c_{t}-c_{t}^{*}\right)-\left(p_{t}-p_{t}^{*}\right)+\left(1-\sigma_{1}\right)\left(\tau_{t}-\tau_{t}^{*}\right) .
$$

Production function:

$$
\left(z_{t}-z_{t}^{*}\right)=\left(a_{t}-a_{t}^{*}\right)+\alpha\left(k_{t-1}-k_{t-1}^{*}\right)+(1-\alpha)\left(l_{t}-l_{t}^{*}\right) .
$$


The linearized price setting rule for domestic sales by local currency pricing $(l c p)$ firms is:

$$
\begin{aligned}
& {[v]\left(y_{H t}(l c p)-y_{H t}\right)+m c_{t}-[1+\nu] p_{H t}+\left[\nu-(1+\beta) v \psi_{P}\right] p_{H t}(l c p)} \\
& +\left[v \psi_{P}\right] p_{H t-1}(l c p)+\left[\beta v \psi_{P}\right] E_{t} p_{H t+1}(l c p)=0
\end{aligned}
$$

where

$$
m c_{t}=p_{t}+r_{t}-a_{t}+(1-\alpha) k_{t-1}-(1-\alpha) l_{t}
$$

The linearized price setting rule for domestic sales is the same for producer currency pricing ( $p c p)$ firms:

$$
\begin{aligned}
& {[v]\left(y_{H t}(p c p)-y_{H t}\right)+m c_{t}-[1+\nu] p_{H t}+\left[\nu-(1+\beta) v \psi_{P}\right] p_{H t}(p c p)} \\
& +\left[v \psi_{P}\right] p_{H t-1}(p c p)+\left[\beta v \psi_{P}\right] E_{t} p_{H t+1}(p c p)=0 .
\end{aligned}
$$

Given that all local currency pricing firms set the same price as each other, and all producer currency pricing firms as each other, we may write the linearized form of the home domestic goods price index as:

$$
p_{H t}=\eta p_{H t}(l c p)+(1-\eta) p_{H t}(p c p) .
$$

Substituting in the price-setting equations above, we find the overall price level of home goods sold at home:

$$
m c_{t}-\left[1+(1+\beta) v \psi_{P}\right] p_{H t}+\left[v \psi_{P}\right] p_{H t-1}+\left[\beta v \psi_{P}\right] E_{t} p_{H t+1}=0 .
$$

The foreign counterpart is

$$
m c_{t}^{*}-\left[1+(1+\beta) v \psi_{P}\right] p_{F t}^{*}+\left[v \psi_{P}\right] p_{F t-1}^{*}+\left[\beta v \psi_{P}\right] E_{t} p_{F t+1}^{*}=0
$$

where

$$
m c_{t}^{*}=p_{t}^{*}+r_{t-1}^{*}-a_{t}^{*}+(1-\alpha) k_{t-1}^{*}-(1-\alpha) l_{t}^{*} .
$$

Similarly, the linearized price setting rule when home local currency pricing firms $(i=0, \ldots, \eta)$ export is:

$$
\begin{aligned}
& {[\nu]\left(y_{H t}^{*}(l c p)-y_{H t}^{*}\right)+m c_{t}-[1+\nu] p_{H t}^{*}+\left[\nu-(1+\beta) v \psi_{P}\right] p_{H t}^{*}(l c p)} \\
& +\left[v \psi_{P}\right] p_{H t-1}^{*}(l c p)+\left[\beta v \psi_{P}\right] E_{t} p_{H t+1}^{*}(l c p)-s_{t}=0 .
\end{aligned}
$$

And for producer currency pricing firms, this is:

$$
\begin{aligned}
& {[v]\left(y_{H t}^{*}(p c p)-y_{H t}^{*}\right)+m c_{t}-[1+\nu] p_{H t}^{*}+\left[\nu-(1+\beta) v \psi_{P}\right] p_{H t}^{*}(p c p)} \\
& +\left[v \psi_{P}\right] p_{H t-1}^{*}(p c p)+\left[\beta v \psi_{P}\right] E_{t} p_{H t+1}^{*}(p c p)-[1+\nu] s_{t}=0 .
\end{aligned}
$$

Since the linearized form of the home export price index implies:

$$
p_{H t}^{*}=\eta p_{H t}^{*}(l c p)+(1-\eta) p_{H t}^{*}(p c p)-(1-\eta) s_{t},
$$


we can substitute in the pricing equations to write an equation for this export price index as:

$$
\begin{aligned}
& m c_{t}-\left[1+(1+\beta) v \psi_{P}\right] p_{H t}^{*}+\left[v \psi_{P}\right] p_{H t-1}^{*}+\left[\beta v \psi_{P}\right] E_{t} p_{H t+1}^{*}-\left[(1-\eta)(1+\beta) \nu \psi_{P}+1\right] s_{t} \\
& +(1-\eta) \nu \psi_{P} s_{t-1}+(1-\eta) \beta \nu \psi_{P} E_{t}\left[s_{t+1}\right]=0 .
\end{aligned}
$$

The counterpart for foreign country exports to the home country is:

$$
\begin{aligned}
& m c_{t}^{*}-\left[1+(1+\beta) v \psi_{P}\right] p_{F t}+\left[v \psi_{P}\right] p_{F t-1}+\left[\beta v \psi_{P}\right] E_{t} p_{f t+1}+[(1-\eta)(1+\nu)+1] s_{t} \\
& -(1-\eta) \nu \psi_{P} s_{t-1}-(1-\eta) \beta \nu \psi_{P} E_{t}\left[s_{t+1}\right]=0 .
\end{aligned}
$$

Then combine these four pricing equations to get:

$$
\left(m c_{t}-m c_{t}^{*}\right)-\left[1+(1+\beta) v \psi_{P}\right]\left(p_{H t}-p_{F t}^{*}\right)+\left[v \psi_{P}\right]\left(p_{H t-1}-p_{F t-1}^{*}\right)+\left[\beta v \psi_{P}\right] E_{t}\left(p_{H t+1}-p_{F t+1}^{*}\right)=0
$$

and

$$
\begin{aligned}
& -\left(m c_{t}-m c_{t}^{*}\right)-\left[1+(1+\beta) v \psi_{P}\right]\left(p_{F t}-p_{H t}^{*}\right)+\left[v \psi_{P}\right]\left(p_{F t-1}-p_{H t-1}^{*}\right) \\
& +\left[\beta v \psi_{P}\right]\left(E_{t}\left(p_{F t+1}\right)-E_{t}\left(p_{H t+1}^{*}\right)\right)-2\left[(1-\eta)(1+\beta) \nu \psi_{P}+1\right] s_{t} \\
& +2(1-\eta) \nu \psi_{P} s_{t-1}+2(1-\eta) \beta \nu \psi_{P} E_{t}\left[s_{t+1}\right]=0 .
\end{aligned}
$$

Ratio of price indexes:

$$
\begin{aligned}
p_{t} & =\bar{\theta} p_{H t}+(1-\bar{\theta}) p_{F t}+\bar{\theta} \log \left(1-\theta_{t}\right) \\
p_{t}^{*} & =(1-\bar{\theta}) p_{H t}^{*}+\bar{\theta} p_{F t}^{*}+\bar{\theta} \log \left(1-\theta_{t}\right)
\end{aligned}
$$

so

$$
\left(p_{t}-p_{t}^{*}\right)=(1-\bar{\theta})\left(p_{F t}-p_{H t}^{*}\right)+\bar{\theta}\left(p_{H t}-p_{F t}^{*}\right)
$$

Demands are

$$
\begin{aligned}
& y_{H t}=y_{t}+\mu p_{t}-\mu p_{H t}+\theta_{t} \\
& y_{F t}=y_{t}+\mu p_{t}-\mu p_{F t}-\left(\frac{\bar{\theta}}{1-\bar{\theta}}\right) \theta_{t} \\
& y_{F t}^{*}=y_{t}^{*}+\mu p_{t}^{*}-\mu p_{F t}^{*}+\theta_{t}^{*} \\
& y_{H t}^{*}=y_{t}^{*}+\mu p_{t}^{*}-\mu p_{H t}^{*}-\left(\frac{\bar{\theta}}{1-\bar{\theta}}\right) \theta_{t}^{*}
\end{aligned}
$$

so

$$
\begin{aligned}
& \left(y_{H t}-y_{F t}^{*}\right)=\left(y_{t}-y_{t}^{*}\right)+\mu\left(p_{t}-p_{t}^{*}\right)-\mu\left(p_{H t}-p_{F t}^{*}\right)+\left(\theta_{t}-\theta_{t}^{*}\right) \\
& \left(y_{F t}-y_{H t}^{*}\right)=\left(y_{t}-y_{t}^{*}\right)+\mu\left(p_{t}-p_{t}^{*}\right)-\mu\left(p_{F t}-p_{H t}^{*}\right)-\left(\frac{\bar{\theta}}{1-\bar{\theta}}\right)\left(\theta_{t}-\theta_{t}^{*}\right) .
\end{aligned}
$$


Capital accumulation:

$$
\begin{array}{cc}
(1+\beta) \psi_{I} k_{t}-\beta \psi_{I} E_{t} k_{t+1}-\psi_{I} k_{t-1}-(1-\beta(1-\bar{\delta})) r_{t+1}+\beta \bar{\delta} \delta_{t} & \\
-\sigma_{1} c_{t}+\sigma_{1} E_{t} c_{t+1}+\left(1-\sigma_{1}\right) \tau_{c t}-\left(1-\sigma_{1}\right) E_{t}\left[\tau_{c t+1}\right] & =0 .
\end{array}
$$

combined with foreign:

$$
\begin{aligned}
& (1+\beta) \psi_{I}\left(k_{t}-k_{t}^{*}\right)-\beta \psi_{I} E_{t}\left(k_{t+1}-k_{t+1}^{*}\right)-\psi_{I}\left(k_{t-1}-k_{t-1}^{*}\right) \\
& -(1-\beta(1-\bar{\delta}))\left(r_{t}-r_{t}^{*}\right)-\sigma_{1}\left(c_{t}-c_{t}^{*}\right) \\
& +\sigma_{1} E_{t}\left(c_{t+1}-c_{t+1}^{*}\right)+\left(1-\sigma_{1}\right)\left(\tau_{c t}-\tau_{c t}^{*}\right)-\left(1-\sigma_{1}\right) E_{t}\left(\tau_{c t+1}-\tau_{c t+1}^{*}\right)=0
\end{aligned}
$$

Capital stock transition function:

$$
\bar{\delta}\left(i_{t}-i_{t}^{*}\right)=\left(k_{t}-k_{t}^{*}\right)-(1-\delta)\left(k_{t-1}-k_{t-1}^{*}\right) .
$$

Capital-labor tradeoff:

$$
\left(p_{t}-p_{t}^{*}\right)+\left(r_{t}-r_{t}^{*}\right)+\left(k_{t-1}-k_{t-1}^{*}\right)=\left(w_{t}-w_{t}^{*}\right)+\left(l_{t}-l_{t}^{*}\right)
$$

Define final goods demand: ${ }^{20}$

$$
\left(y_{t}-y_{t}^{*}\right)=\frac{\bar{C}}{\bar{Y}}\left(c_{t}-c_{t}^{*}\right)+\frac{\bar{I}}{\bar{Y}}\left(i_{t}-i_{t}^{*}\right)+\frac{\bar{G}}{\bar{Y}}\left(\tau_{d t}-\tau_{d t}^{*}\right) .
$$

Goods market clearing conditions are

$$
\begin{aligned}
\bar{\theta} y_{H t}+(1-\bar{\theta}) y_{H t}^{*} & =z_{t} \\
(1-\bar{\theta}) y_{F t}+\bar{\theta} y_{F t}^{*} & =z_{t}^{*},
\end{aligned}
$$

so combining:

$$
\bar{\theta}\left(y_{H t}-y_{F t}^{*}\right)-(1-\bar{\theta})\left(y_{F t}-y_{H t}^{*}\right)=\left(z_{t}-z_{t}^{*}\right) .
$$

Define trade balance: (taking $X$ as a share of GDP, $Z$ )

$$
\left[\frac{1}{1-\bar{\theta}}\right] x_{t}=s_{t}-\left(p_{F t}-p_{H t}^{*}\right)-\left(y_{F t}-y_{H t}^{*}\right) \text {. }
$$

Compute the current account as the inverse of the capital account (as share of GDP):

$$
c a_{t}=\left(b_{t}-\bar{s} b_{t}^{*}\right)-\left(b_{t-1}-\bar{s} b_{t-1}^{*}\right)
$$

Rewrite the balance of payments condition (deviations as shares of GDP): Given parameter values, $\beta, \delta, \alpha, \sigma_{1}, \sigma_{3}, \bar{G}$, I can define the steady state value of $A$ so that the steady state value of $I$ is
any desired fraction of $\bar{Y}$, and then the steady state value of $C$ is just $\bar{Y}-\bar{I}-\bar{G}$. I use $\frac{\bar{I}}{\bar{Y}}=\frac{\bar{G}}{\bar{Y}}=0.20$. 


$$
x_{t}+\frac{1}{\beta}\left(b_{t-1}-\bar{s} b_{t-1}^{*}\right)-\left(b_{t}-\bar{s} b_{t}^{*}\right)=0 .
$$

Linearize the interest rate parity condition, as discussed above:

$$
i_{t}-i_{t}^{*}=\frac{1}{1-\beta}\left(E_{t} s_{t+1}-s_{t}\right)-\Psi_{B}\left(b_{t}-\bar{s} b_{t}^{*}\right)+\xi_{t} .
$$

\subsection{Econometric Methods}

The contemporaneous covariances matrix, $R_{y^{*}}(0)$, can be written as follows :

$$
R_{y^{*}}(0) \equiv E\left[y_{t}^{*} y_{t}^{* \prime}\right]=\Sigma+\sum_{i=0}^{\infty}\left[B D^{i}(D-I) B^{-1}\right] \Sigma\left[B D^{i}(D-I) B^{-1}\right]^{\prime}
$$

where $D$ is the diagonal matrix of eigenvalues and $B$ the matrix of eigen vectors of $A_{1} . R_{y^{*}}(0)$ can then be computed:

$$
R_{y^{*}}(0)=\Sigma+B[K] B^{\prime}
$$

where the typical element $(\mathrm{i}, \mathrm{j})$ of $\mathrm{K}$ is

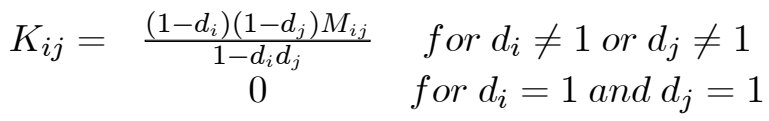

and where

$$
M=B^{-1} \Sigma B^{-1^{\prime}} .
$$

Once $R_{y^{*}}(0)$ is computed, the covariances across one lag $R_{y^{*}}(1)$ may be found:

$$
R_{y^{*}}(1)=E\left[y_{t}^{*} y_{t}^{* \prime}\right]=A R_{y^{*}}(0)-\Sigma
$$

and over lags greater than one:

$$
R_{y^{*}}(k)=E\left[y_{t}^{*} y_{t-k}^{* \prime}\right]=A^{k-1} R_{y^{*}}(1) \text { for } k>1 \text {. }
$$

The full covariance matrix, $\Omega$, then can be constructed by assembling the blocks for various lags. In particular, the only parts of each covariance block used are those relating to the particular data series to be fit, where $x_{t}$ is the relevant portion of $y^{*}$ (in percent deviations from the previous period). 
Further, to reduce numerical problems associated with rounding error, lags of only up to 15 periods are currently used, with covariances assumed to be zero over lags greater than 15 periods. 


\subsection{References}

Ahmed, S., Ickes, B., Wang, P., Yoo, B.S., 1993. International business cycles. American Economic Review 83, 335-359.

Bergin, P., 2003. Putting the new open economy macroeconomics to a test. Journal of International Economics 60, 3-34.

Bergin, P., Sheffrin, S., 2000. Interest rates, exchange rates, and present value models of the current account. The Economic Journal 110, 535-558.

Betts, C., Devereux, M.B., 2000. Exchange rate dynamics in a model of pricing-to-market. Journal of International Economics 50, 215-244.

Devereux, M.B., C. Engel, 2002. Exchange rate pass-through, exchange rate volatility, and exchange rate disconnect. Journal of Monetary Economics 49, 913-940.

Duarte, M., Stockman, A., 2001. Rational speculation and exchange rates. NBER Working Paper 8362.

Eichenbaum, M., Evans, C.L., 1995. Some empirical evidence on the effects of shocks to monetary policy on exchange rates. Quarterly Journal of Economics 110, 975-1009.

Faust, J., Rogers, J.H., 2003. Monetary policy's role in exchange rate behavior. Journal of Monetary Economics 50, 1403-1424.

Flood, R., Rose, A., 1999. Understanding exchange rate volatility without the contrivance of macroeconomics. Economic Journal 109, 660-672.

Ghironi, F., Iscan, T., Rebucci, A., 2003. Productivity shocks and consumption smoothing in the international economy. Mimeo, Boston College.

Ghosh, A.R., 1995. International capital mobility among the major industrialised countries: too little or too much? Economic Journal 105, 107-128.

Harrigan, J., 1993. OECD imports and trade barriers in 1983. Journal of International Economics 35, 91-111.

Ireland, P., 1997. A small, structural, quarterly model for monetary policy evaluation. CarnegieRochester Conference Series on Public Policy 47, 83-108.

Ireland, P., 2001. Sticky-price models of the business cycle: specification and stability. Journal of 
Monetary Economics 47, 3-18.

Jeanne, O., Rose, A., 2002. Noise trading and exchange rate regimes. Quarterly Journal of Economics $117,537-569$.

Kim, J., 2000. Constructing and estimating a realistic optimizing model of monetary policy. Journal of Monetary Economics 45, 329-359.

Kollmann, R., 2001. Macroeconomic effects of nominal exchange rates regimes: New insights into the role of price dynamics. University of Bonn mimeo.

Kollmann, R., 2002. Monetary policy rules in the open economy: effects on welfare and business cycles. Journal of Monetary Economics 49, 989-1015.

Lane, P.R., Milesi-Ferretti, G.M., 2002. Long-term capital movements. NBER Macroeconomics Annual, 73-116.

Leeper, E., Sims, C., 1994. Toward a modern macroeconomic model usable for policy analysis. NBER Macroeconomic Annual, 81-118.

Lewis, K., 1995. Puzzles in International Financial Markets. In: Grossman, G., Rogoff, K. (Eds.), Handbook of International Economics, Vol. III. Elsevier, Amsterdam, pp. 1913-1971.

Lubik, T., Schorfheide, F., 2002. Testing for indeterminacy: An application to U.S. monetary policy. American Economic Review forthcoming.

Mark, N., Wu, Y., 1998. Rethinking deviations from uncovered interest parity: The role of covariance risk and noise. Economic Journal 108, 1686-1706.

McCallum, B., Nelson, E., 1999. Nominal income targeting in an open-economy optimizing model. Journal of Monetary Economics 43, 553-578.

McCallum, B., Nelson, E., 2000. Monetary policy for an open economy: An alternative framework with optimizing agents and sticky prices. Oxford Review of Economic Policy 16, 74-91.

Meese, R.A., Rogoff, K., 1983. Empirical exchange rate models of the seventies: do they fit out of sample? Journal of International Economics 14, 3-24.

Nason, J.M., Rogers, J.H., 2003. The present-value model of the current account has been rejected: roundup the usual suspects, Federal Reserve Bank of Atlanta Working Paper 2003-7a.

Obstfeld, M., Rogoff, K., 2000. New directions for stochastic open economy models. Journal of 
International Economics 50, 117-153.

Obstfeld, M., Rogoff, K., 2002. Risk and exchange rates. In: Helpman, E., Sadka, E. (Eds.), Contemporary Economic Policy: Essays in Honor of Assaf Razin. Cambridge University Press, Cambridge.

Pesenti, P., 2002. International Monetary Policy Cooperation and Financial Market Integration, discussant comments at European Central Bank International Research Forum on Monetary Policy, Frankfurt, July.

Rogers, J., 1999. Monetary shocks and real exchange rates. Journal of International Economics 49, 269-288.

Schmitt-Grohe, S., Uribe, M., 2003. Closing small open economy models. Journal of International Economics 61, 163-185.

Sheffrin, S., Woo, W. T., 1990. Present value tests of an intertemporal model of the current account. Journal of International Economics 29, 237-253.

Smets, F., Wouters, R., 2002. Monetary policy in an estimated stochastic dynamic general equilibrium model of the euro area. ECB mimeo. 
Table 1: Unit Root Tests

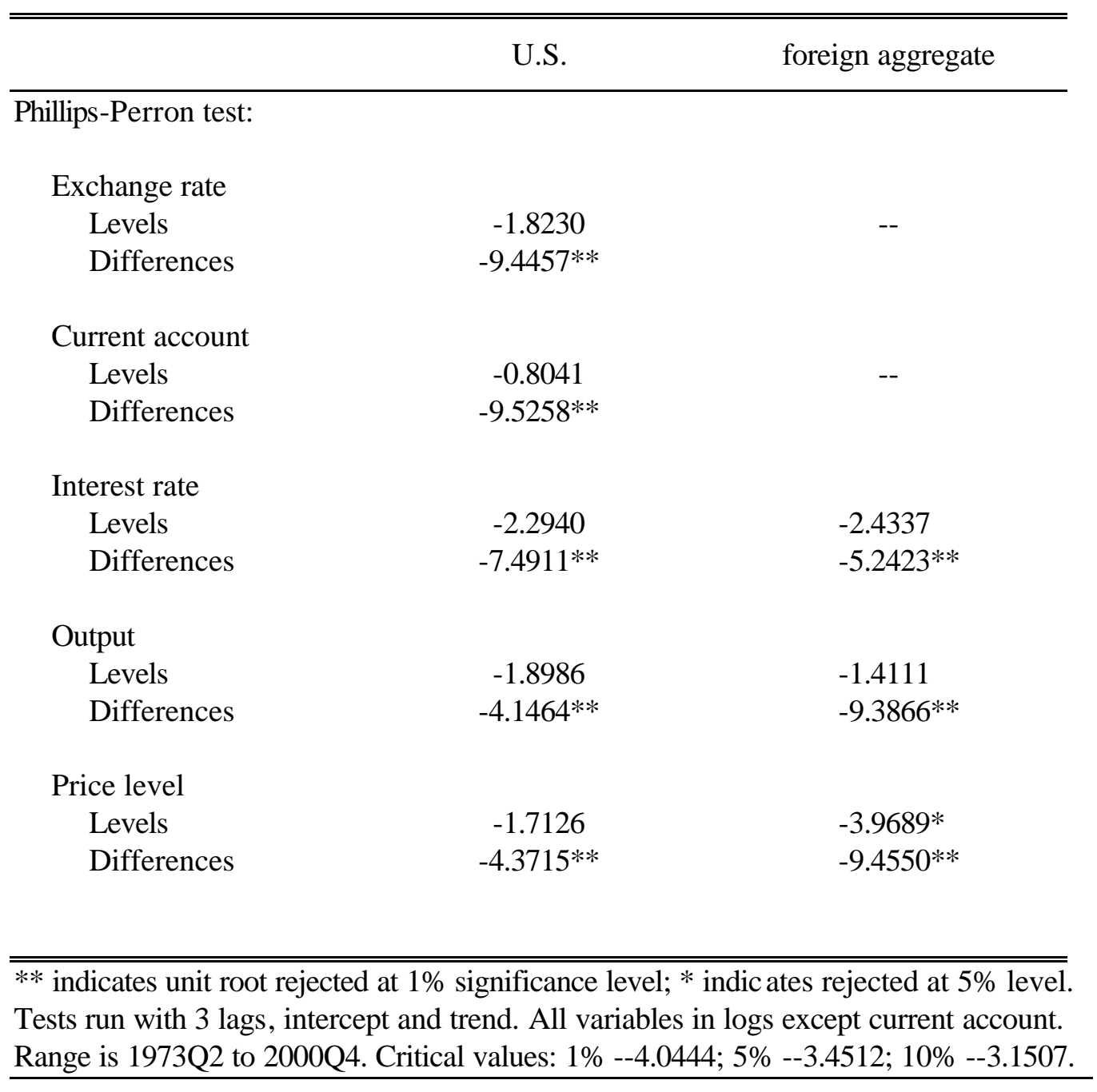


Table 2: Estimation Results

\begin{tabular}{|c|c|c|}
\hline \multicolumn{3}{|c|}{ Measures of Fit: } \\
\hline \multicolumn{3}{|c|}{ log likelihood value: } \\
\hline \multirow{2}{*}{\multicolumn{2}{|c|}{$\begin{array}{l}\text { model } \\
\text { standard VAR }\end{array}$}} & 1797.55 \\
\hline & & 1823.78 \\
\hline \multicolumn{3}{|l|}{$\underline{\text { Schwarz criterion }}$} \\
\hline \multicolumn{2}{|l|}{ model } & 1741.14 \\
\hline \multicolumn{2}{|l|}{ standard VAR } & 1642.81 \\
\hline \multicolumn{3}{|c|}{ RMSE: structural model / standard VAR } \\
\hline \multirow{5}{*}{\multicolumn{2}{|c|}{$\begin{array}{l}\text { exchange rate } \\
\text { current account } \\
\text { interest rate } \\
\text { output } \\
\text { price level }\end{array}$}} & 1.013 \\
\hline & & 1.019 \\
\hline & & 1.104 \\
\hline & & 1.092 \\
\hline & & 1.171 \\
\hline \multicolumn{3}{|c|}{ RMSE: structural model / random walk } \\
\hline \multirow{5}{*}{\multicolumn{2}{|c|}{$\begin{array}{l}\text { exchange rate } \\
\text { current account } \\
\text { interest rate } \\
\text { output } \\
\text { price level }\end{array}$}} & 0.984 \\
\hline & & 0.986 \\
\hline & & 0.997 \\
\hline & & 1.045 \\
\hline & & 1.037 \\
\hline \multicolumn{3}{|c|}{ Parameter Estimates: } \\
\hline \multicolumn{3}{|c|}{ behavioral parameters: } \\
\hline $\begin{array}{l}\text { consumption } \\
\text { elasticity term }\end{array}$ & $\sigma_{1}$ & $\begin{array}{c}1.072 \\
(0.006)\end{array}$ \\
\hline $\begin{array}{l}\text { money demand } \\
\text { elasticity term }\end{array}$ & $\sigma_{2}$ & $\begin{array}{c}0.253 \\
(0.003)\end{array}$ \\
\hline $\begin{array}{l}\text { Investment } \\
\text { adjustment cost }\end{array}$ & $\psi_{I}$ & $\begin{array}{l}21.523 \\
(0.512)\end{array}$ \\
\hline $\begin{array}{l}\text { Price adjustment } \\
\text { cost }\end{array}$ & $\psi_{P}$ & $\begin{array}{l}31.099 \\
(2.414)\end{array}$ \\
\hline bond cost & $\psi_{B}$ & $\begin{array}{c}0.00384 \\
(0.00010)\end{array}$ \\
\hline $\begin{array}{l}\text { share of local cur- } \\
\text { rency pricing }\end{array}$ & $\eta$ & $\begin{array}{c}0.999 \\
(0.000)\end{array}$ \\
\hline $\begin{array}{l}\text { elasticity of subst. } \\
\text { home-foreign goods }\end{array}$ & $\mu$ & $\begin{array}{l}1.130 \\
(0.062)\end{array}$ \\
\hline \multicolumn{3}{|c|}{ monetary policy rule parameters: } \\
\hline response to inflation & $a_{1}$ & $\begin{array}{c}0.9891 \\
(0.0002)\end{array}$ \\
\hline response to output & $a_{2}$ & $\begin{array}{c}0.0001 \\
(0.0000)\end{array}$ \\
\hline $\begin{array}{l}\text { response to the } \\
\text { exchange rate }\end{array}$ & $a_{3}$ & $\begin{array}{c}0.1128 \\
(0.0138)\end{array}$ \\
\hline
\end{tabular}




\begin{tabular}{|c|c|}
\hline technology & $\begin{array}{c}0.9671 \\
(0.0003)\end{array}$ \\
\hline monetary & $\begin{array}{c}0.9309 \\
(0.0089)\end{array}$ \\
\hline tastes & $\begin{array}{c}0.9773 \\
(0.0014)\end{array}$ \\
\hline home bias & $\begin{array}{c}0.8908 \\
(0.0046)\end{array}$ \\
\hline UIP deviation & $\begin{array}{c}0.9750 \\
(0.0034) \\
\end{array}$ \\
\hline \multicolumn{2}{|c|}{ correlations with UIP shock } \\
\hline technology & $\begin{array}{c}0.123 \\
(0.035)\end{array}$ \\
\hline monetary & $\begin{array}{c}0.152 \\
(0.029)\end{array}$ \\
\hline tastes & $\begin{array}{l}-0.845 \\
(0.011)\end{array}$ \\
\hline home bias & $\begin{array}{l}-0.427 \\
(0.016)\end{array}$ \\
\hline
\end{tabular}

Values in parentheses indicate standard errors. 
Table 3: Variance Decompositions

Remove correlated components of interest parity shock

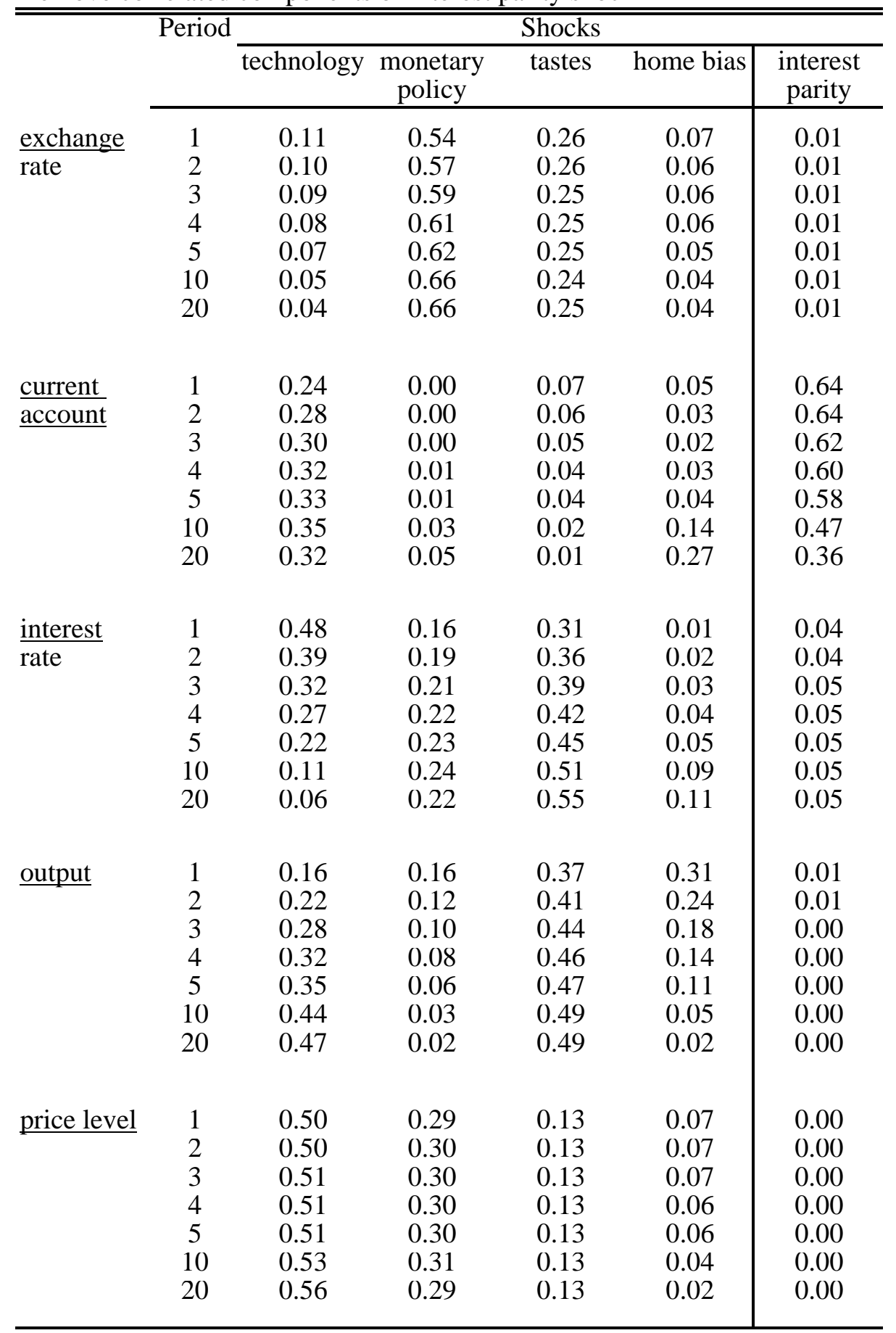


Table 4: Variance Decompositions

Remove correlated components of other shocks with interest parity shock

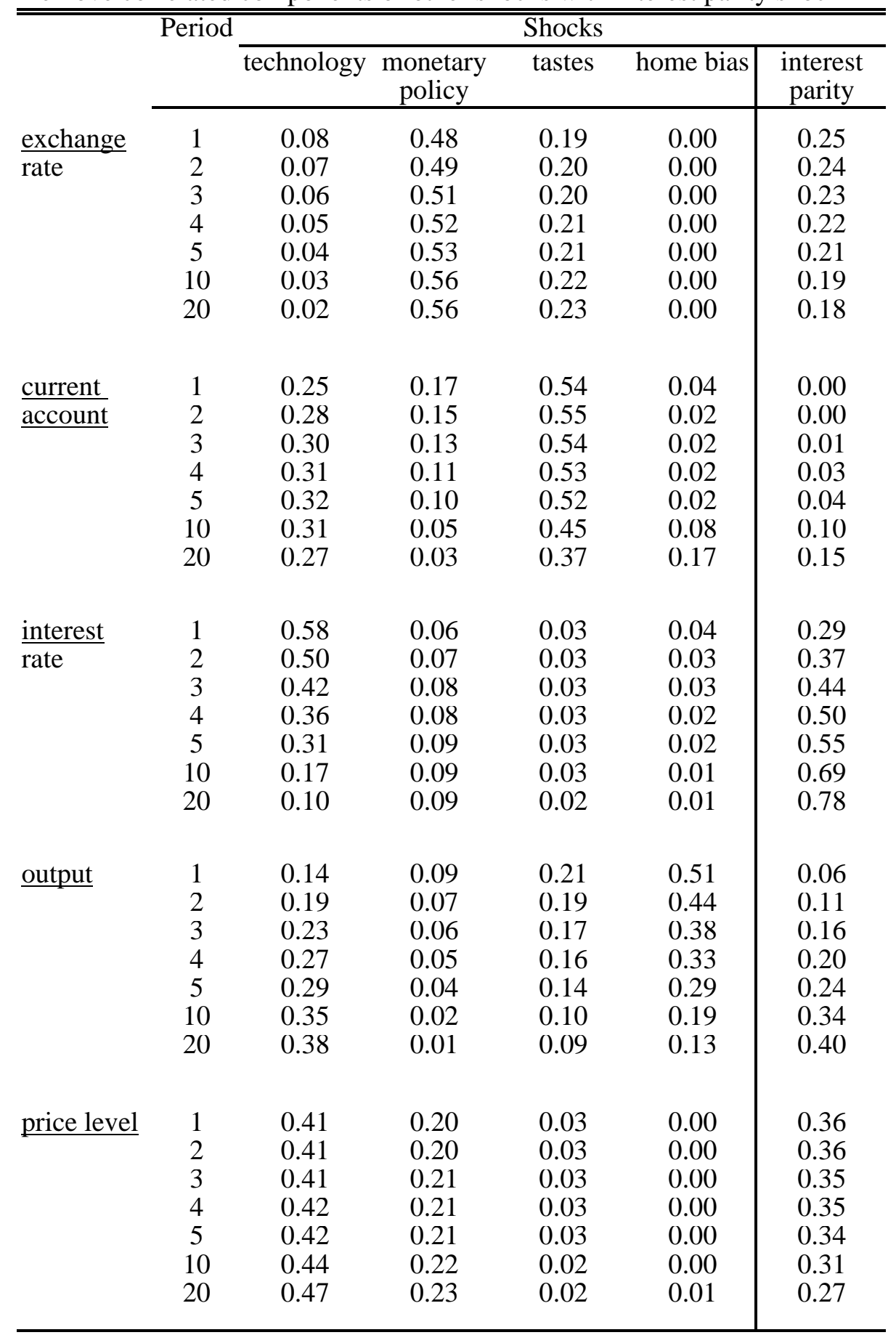


Fig 1: Impulse responses for monetary shock

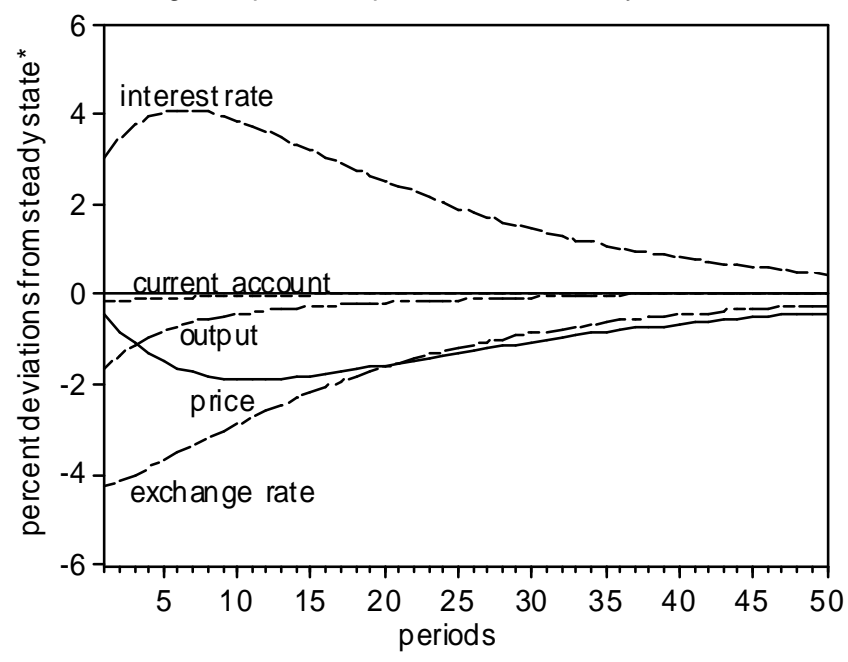

Fig 2: Impulse responses for interest parity shock

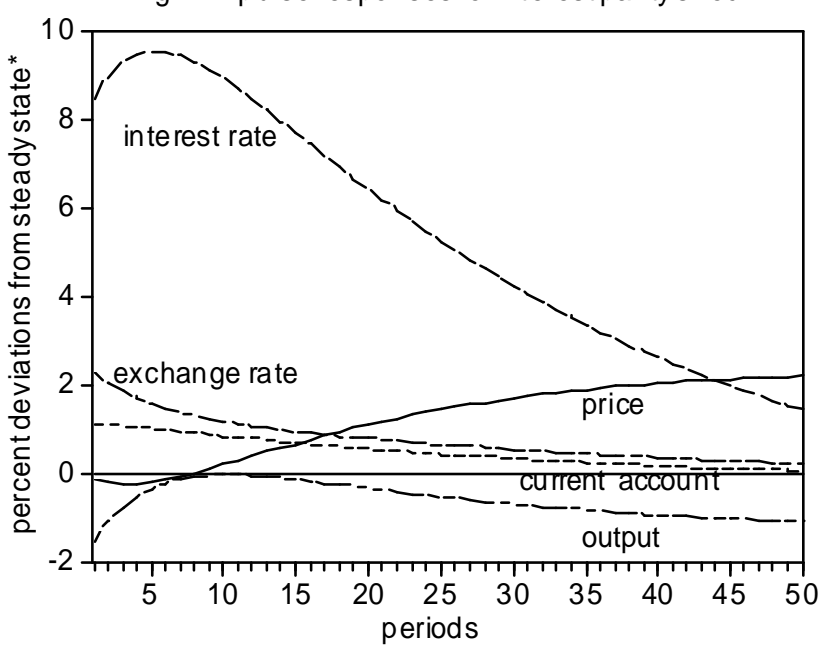

Fig 3: Impulse responses for taste shock

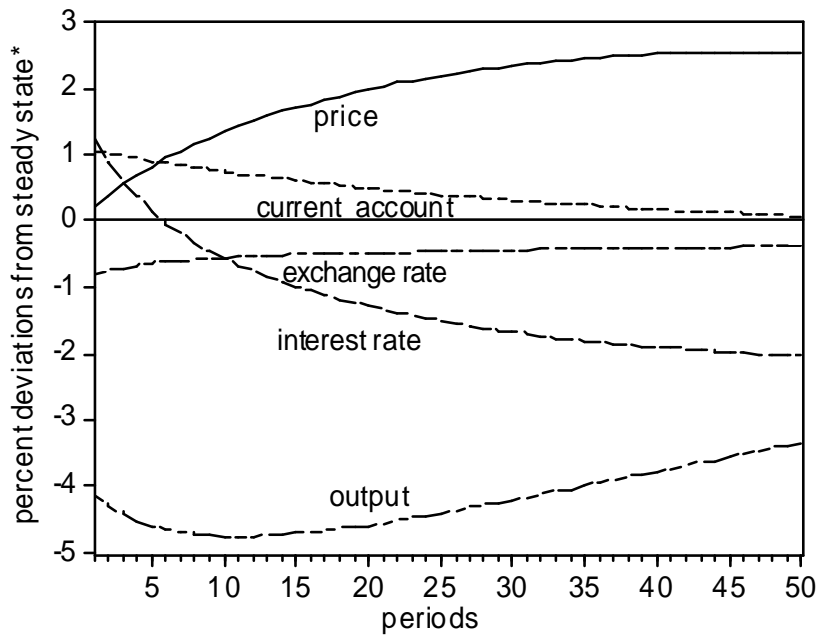

*except current account, which is shown as deviation from steady state as a share of steady state output 